\title{
Study of the Electronic Properties of Solid Polymer Electrolytes Based on Blends of CMC, PEO, and Acetic Acid
}

\author{
Rania Badry ${ }^{1}$, Hanan Elhaes ${ }^{1}$, Nadra Nada ${ }^{1}$, Medhat Ibrahim 2,* (D) \\ Physics Department, Faculty of Women for Arts, Science and Education, Ain Shams University, 11757 Cairo, Egypt \\ Molecular Spectroscopy and Modeling Unit, Spectroscopy Department, National Research Centre, 33 El-Bohouth St., \\ 12622 Dokki, Giza, Egypt \\ * Correspondence: medahmed6@yahoo.com;
}

Scopus Author ID 8641587100

Received: 5.10.2020; Revised: 9.11.2020; Accepted: 11.11.2020; Published: 15.11.2020

\begin{abstract}
The effect of blending on the electronic properties of sodium carboxymethyl cellulose (CMC) and polyethylene oxide (PEO) was studied theoretically using density functional theory (DFT). The CMC and PEO structures were first optimized individually, then were optimized at different blending ratios. All calculations were carried out at the B3LYB/3-21g* level of theory. The changes that occurred in the electronic properties of the individual polymers due to blending were presented in terms of total dipole moment (TDM), the electronic bandgap energy (HOMO/LUMO band gap), and molecular electrostatic potential (MESP). The results indicated that the blended structures were suitable for application in electrochemical devices as the TDM increased, HOMO/LUMO bandgap decreased, and electro-negativity increased. Also, it was concluded that the blended structures' electronic properties were also enhanced by the addition of small concentrations of acetic acid.
\end{abstract}

Keywords: CMC; PEO; B3LYB/3-21g*; TDM; acetic acid and ESP.

(C) 2020 by the authors. This article is an open-access article distributed under the terms and conditions of the Creative Commons Attribution (CC BY) license (https://creativecommons.org/licenses/by/4.0/).

\section{Introduction}

Studying chemical structures with quantum mechanical methods paves the way into investigating materials with modified electronic properties-such class of computational methods elucidates molecules' molecular behavior in many systems. Accordingly, molecular modeling with different levels of theories shows potential applications in many areas [1-3]. It is an accurate, safe, and easy processing method used to study biopolymers and humanmade polymers [4-7]. Among many molecular modeling applications widely applied in studying solid polymer electrolytes (SPEs) [8-10] have steadily increased as they capable of saving time and provides accurate measurements. Moreover, molecular modeling helps understand the mechanism of interaction between polymeric materials [11-15] and can also determine both electrochemical and thermal stabilities for chemical structures [16-18]. Density functional theory (DFT) is the most precise computational method among all known AB Initio methods used in studying polymers' electronic behavior due to its accuracy. Here, DFT was utilized to follow up on the variations of the electronic properties of carboxymethyl cellulose sodium (CMC) due to blending with polyethylene oxide (PEO) to be applicable in the field of SPEs as a membrane material [19-24]. CMC was one of the most useful cellulose derivatives that depend on the substituted hydroxyl groups in its structure [25]. CMC, a natural polysaccharide 
polymer and exists in abundance on earth, has enormous application fields such as food, oil, and cosmetics. Moreover, due to its non-toxicity biocompatibility, carboxymethyl cellulose sodium can be used as a transporter for grafting bone [26-29].

In contrast, PEO was a highly semi-crystalline synthetic polymer that contains both crystalline fractions and amorphous ones in its structure. PEO is a linear polymer and can dissolve in different solvents. However, the high crystallinity of PEO limits its conductivity. So, PEO needs to be blended with other amorphous materials [30-32] or salts to enhance the electronic properties to be used in sensing devices [33-35]. The blending of polymeric materials provides improved and modified physical properties than those of the individual polymers [3336].

Based on the above consideration, the present computational work was conducted. This work aimed to develop a new material based on CMC and PEO blends and another one based on CMC's blends, PEO treated with acetic acid. The investigated electronic properties dedicated the studied blends to be used in energy storage devices.

\section{Materials and Methods}

All calculations were carried out using density functional theory (DFT) as implemented in Gaussian 09 package at Spectroscopy Department, National Research Centre. B3LYB/3$21 \mathrm{~g} *$ level of theory was employed to calculate the electronic properties of individual and blended polymers. In the study of the electronic properties of blended CMC and PEO, four units of CMC (based on ref. 25) and of PEO (that was emeraldine base CMC and emeraldine base $\mathrm{PEO}$ ) were proposed. CMC was interacted with $\mathrm{PEO}$ at blending ratios of (CMC/PEO) as : 4CMC/0PEO, 3CMC/1PEO, 2CMC/2PEO, 1CMC/3PEO and 0CMC/4PEO. Another group of structures based on $\mathrm{CMC} / \mathrm{PEO} / \mathrm{acetic}$ acid was studied at the same level of theory to provide more reactive structures.

\section{Results and Discussion}

The blending of polymeric materials provides an enhancement in the electronic properties of the individual ones that helped electronic applications. Here the effect of blending was discussed in terms of TDM as Debye, HOMO/LUMO energy gap as eV, and ESP. As the shape and size of polymers play a significant role in its electronic properties, CMC was blended with $\mathrm{PEO}$ in different blending ratios: trimer $\mathrm{CMC} /$ monomer $\mathrm{PEO}(3 \mathrm{CMC} / \mathrm{PEO})$, dimer $\mathrm{CMC} /$ dimer PEO (2CMC/2PEO), and monomer $\mathrm{CMC} /$ trimer PEO(1CMC/3PEO). Figure 1 shows the optimized structure of emeraldine base PEO, 3CMC/1PEO, 2CMC/2PEO, and finally, $1 \mathrm{CMC} / 3 \mathrm{PEO}$, respectively. Table 1 presents the calculated values of TDM and HOMO/LUMO bandgap. As a result of computations, TDM of emeraldine base CMC, see ref. [37], was changed considerably due to blending with PEO and vice versa. Where TDM takes values of 40.3945 Debye, 26.8431 Debye, and 14.2747 Debye for blending ratios of CMC/PEO as $3 / 1,2 / 2$, and $1 / 3$ respectively instead of 2.0247 Debye for emeraldine base PEO and that of ref [37] for emeraldine base CMC. 


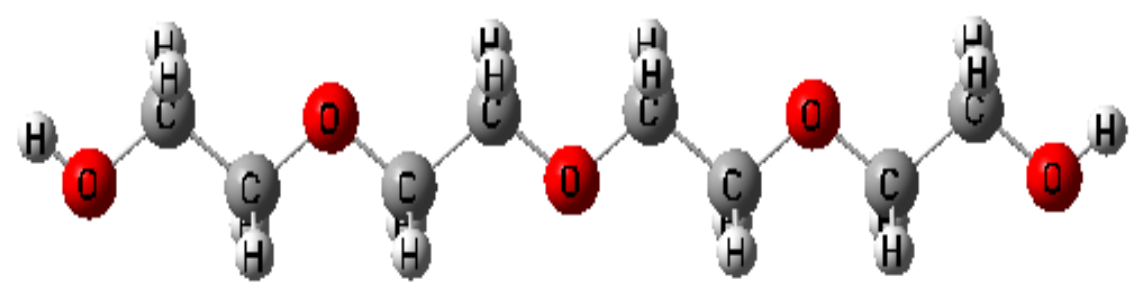

(a)

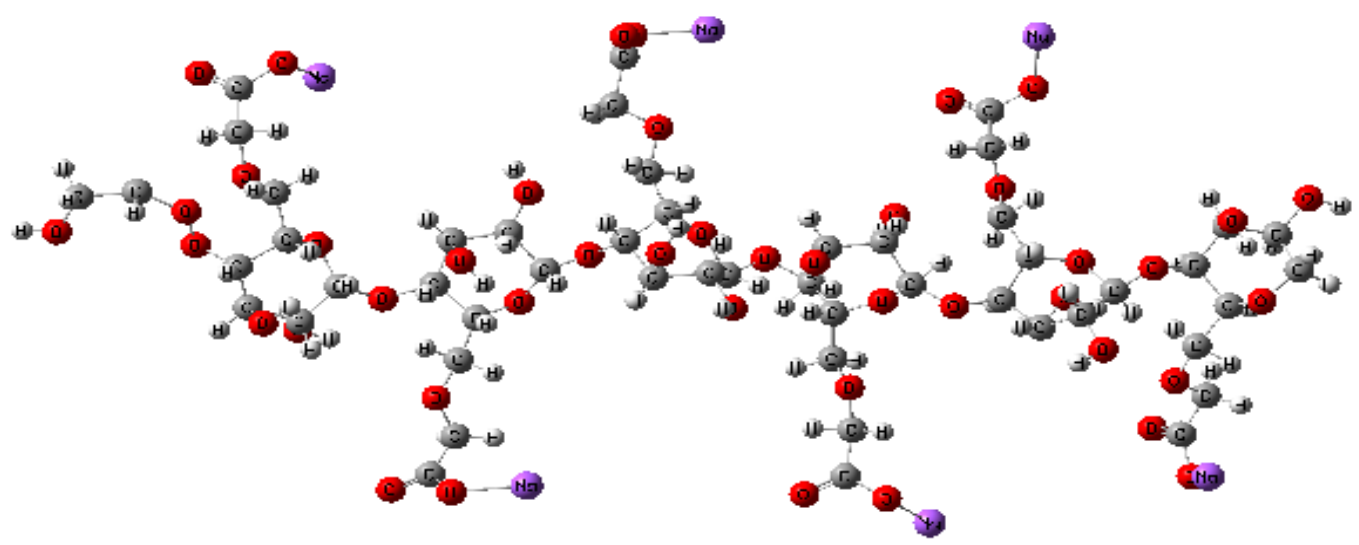

(b)

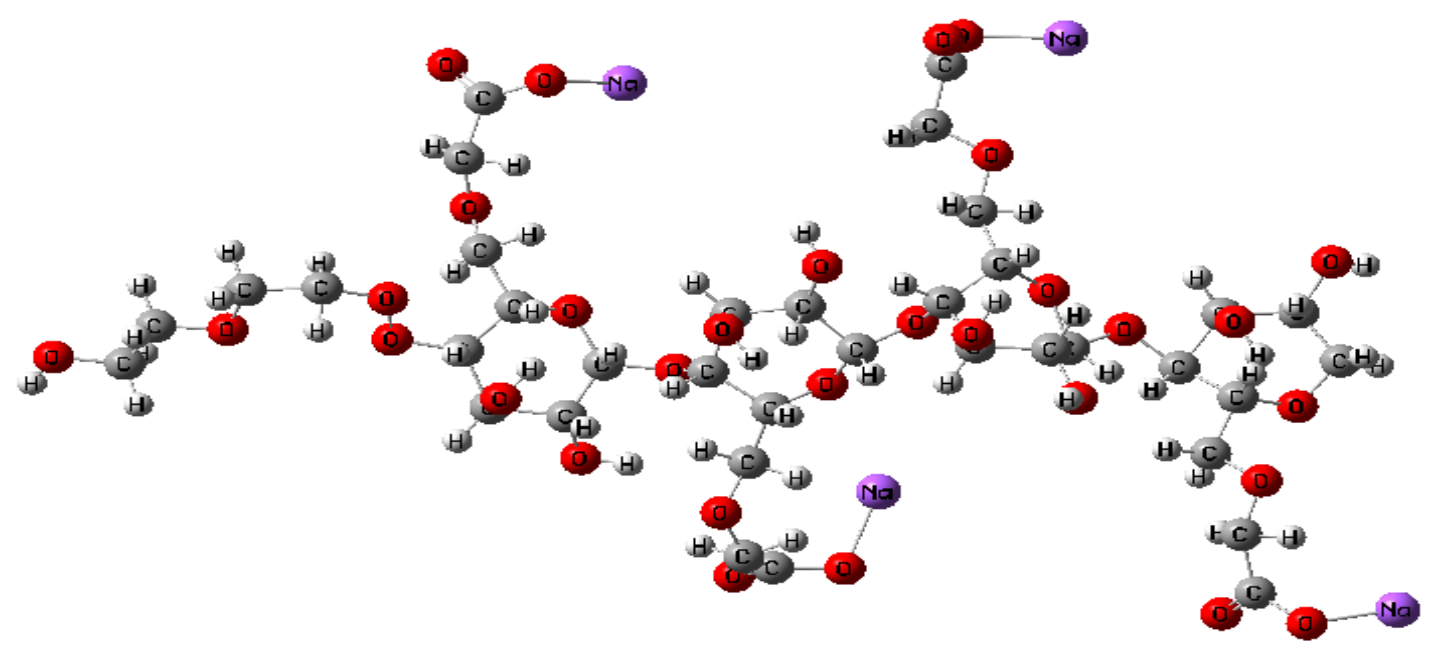

(c)

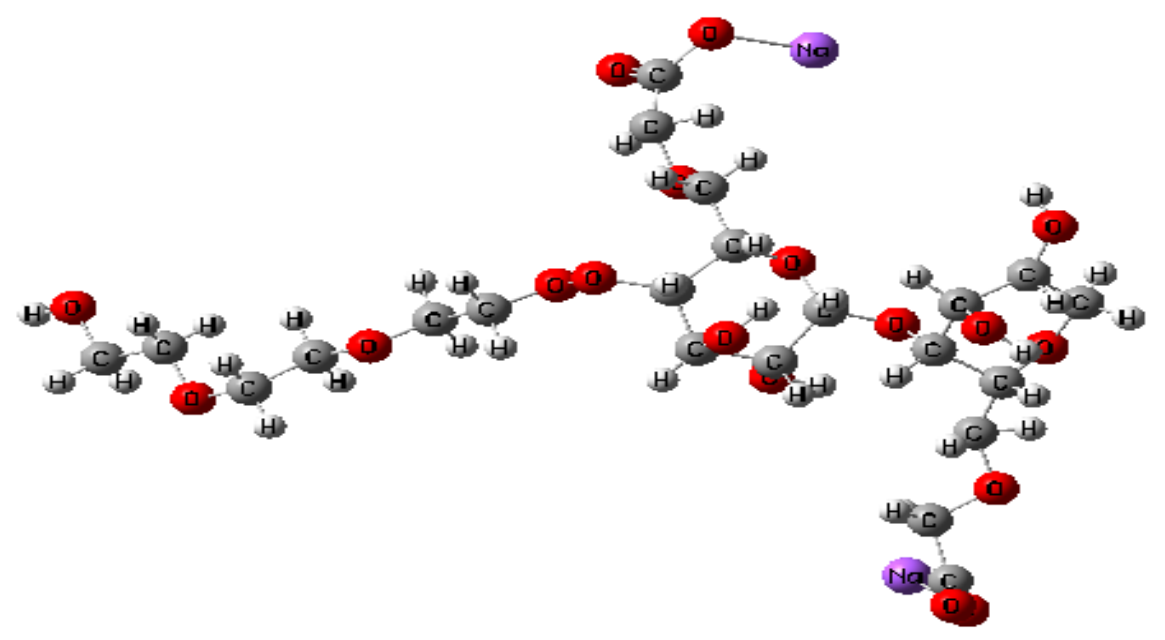

(d)

Figure 1. The optimized structures for a) emeraldine base PEO, b) 3CMC/1PEO, c) $2 \mathrm{CMC} / 2 \mathrm{PEO}$ and d) $1 \mathrm{CMC} / 3 \mathrm{PEO}$. 


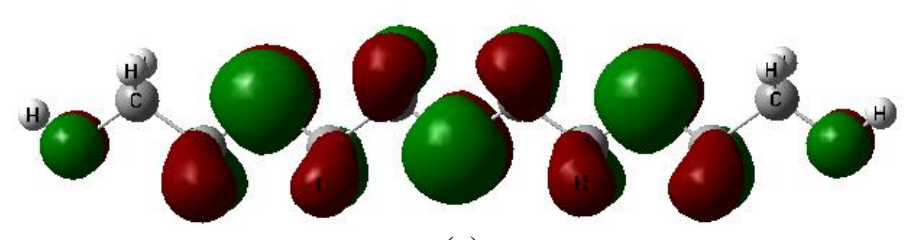

(a)

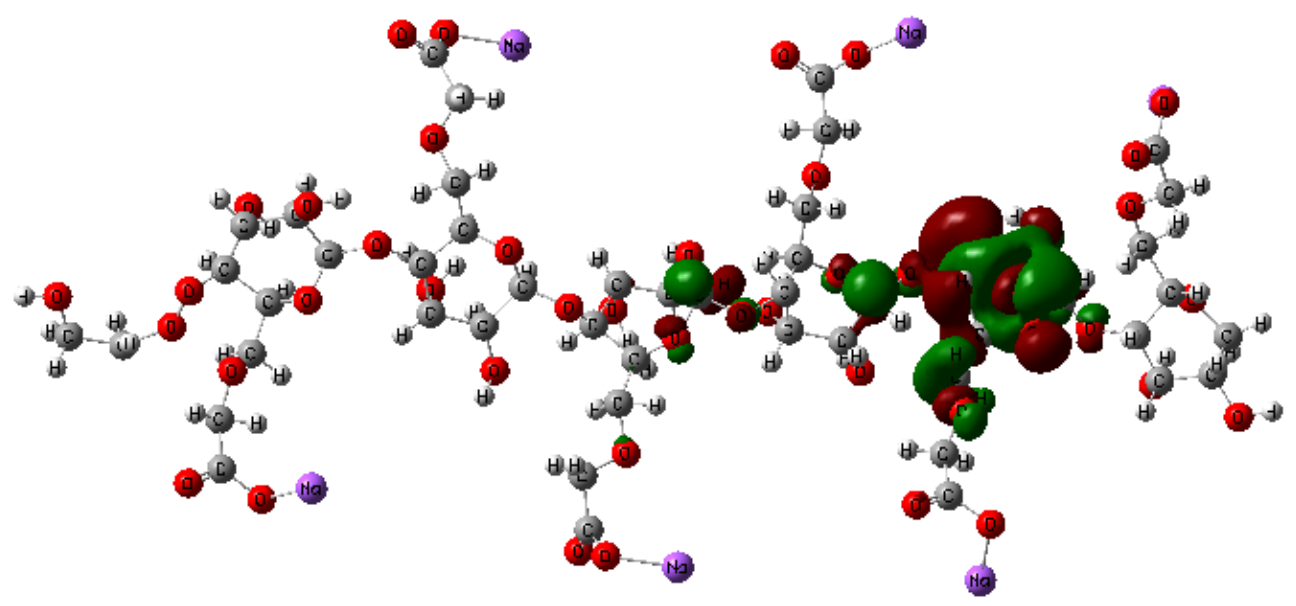

(b)

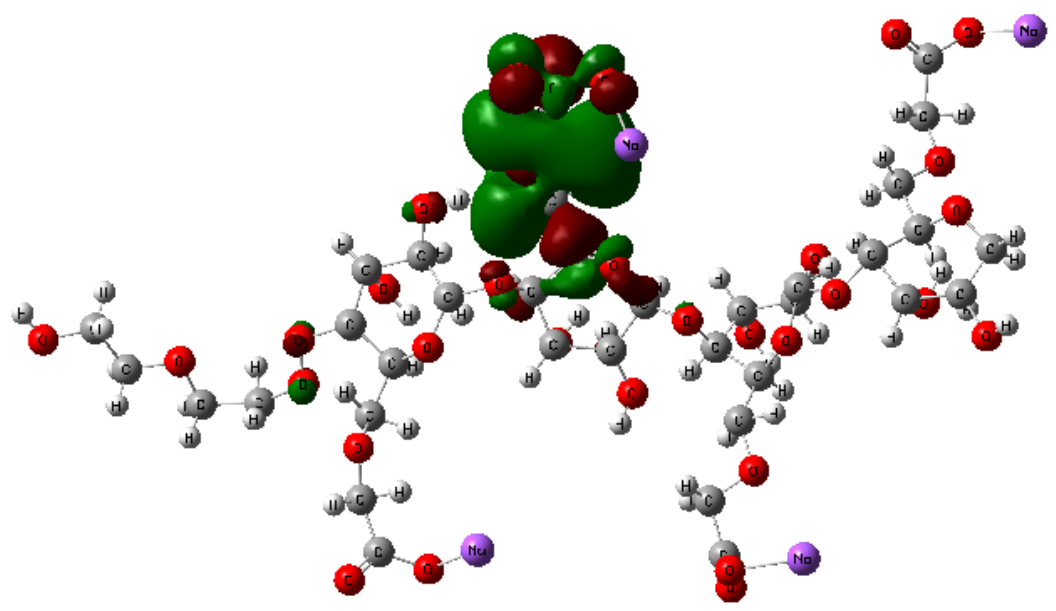

(c)

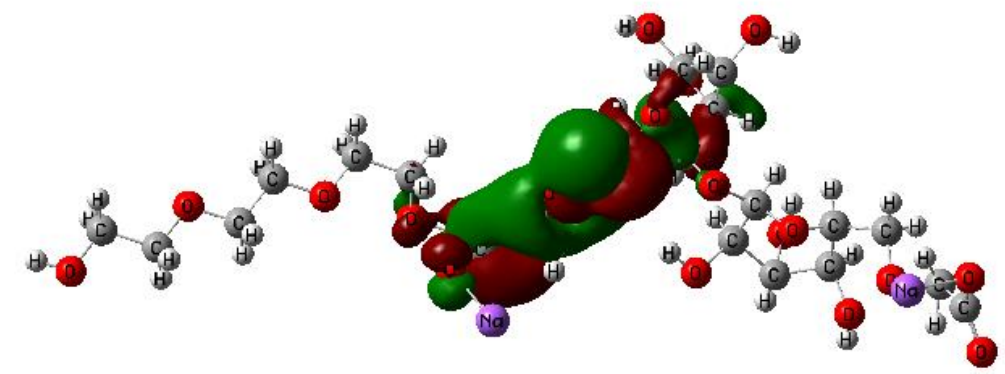

(d)

Figure 2. HOMO/LUMO distribution calculated at B3LYP/3-21g* for a) emeraldine base PEO, b) $3 \mathrm{CMC} / 1 \mathrm{PEO}, \mathrm{c}) 2 \mathrm{CMC} / 2 \mathrm{PEO}$ and d) $1 \mathrm{CMC} / 3 \mathrm{PEO}$.

Table 1. B3LYP/3-21g* calculated TDM as Debye and HOMO-LUMO bandgap energy as eV for emeraldine base PEO, 3CMC/1PEO, 2CMC/2PEO, and 1CMC/3PEO.

\begin{tabular}{l|l|l} 
Structure & TDM & $\Delta \mathbf{E}$ \\
\hline 4PEO & 2.0247 & 8.5227 \\
\hline 3CMC-1PEO & 40.3945 & 0.0705 \\
\hline 2CMC-2PEO & 26.8431 & 0.5728 \\
\hline 1CMC-3PEO & 14.2747 & 1.2335
\end{tabular}


It was obvious from the table that the highest TDM obtained was that for 3CMC/1PEO; however, for the rest of the studied models, TDM was decreased when PEO concentration was equal to or larger than that of CMC in the studied blends. Figure 2, on the other hand, presents the distribution of the highest occupied molecular level and that of the lowest unoccupied one for emeraldine base PEO, 3CMC/1PEO, 2CMC/2PEO, and finally 1CMC/3PEO, respectively.

As presented in ref. [37], the HOMO/LUMO molecular orbitals were distributed over the left edge of emeraldine base CMC only. This behavior of emeraldine base CMC indicated that emeraldine base CMC was only active at its last terminal. On the other hand, for emeraldine base, PEO, the highest and lowest molecular orbitals were distributed over both the edge and the surface, which means that both were highly reactive and that PEO can interact with its surroundings at any position (whether the surface or the edge). This behavior of PEO refers to its ability to be used as a sensor. However, figure 2 shows that the HOMO/LUMO distribution of CMC and PEO in their emeraldine base shape was affected strongly due to blending. The distribution was extended to the second and third $\mathrm{CMC}$ units for 3CMC/1PEO and to the first $\mathrm{CMC}$ unit and either PEO group for both 2CMC/2PEO and 1CMC/3PEO. All these changes in the HOMO/LUMO electronic energy gaps were also depicted in table 1.

As presented in the table, due to blending, emeraldine base CMC's bandgap energy, and that of emeraldine base PEO was changed to $0.0705,0.5728$, and $1.2335 \mathrm{eV}$ for $3 \mathrm{CMC} / 1 \mathrm{PEO}$, $2 \mathrm{CMC} / 2 \mathrm{PEO}$, and 1CMC/3PEO, respectively. The TDM and HOMO/LUMO band gap results indicated that the blending ratio of 3/1 of CMC/PEO possesses the highest TDM and the lowest electronic energy gap. So that, we can conclude that $3 \mathrm{CMC} / 1 \mathrm{PEO}$ blend can be used as a perfect membrane material in storage devices as it possesses TDM of 40.3945 Debye and HOMO/LUMO energy gap of $0.0705 \mathrm{eV}$.

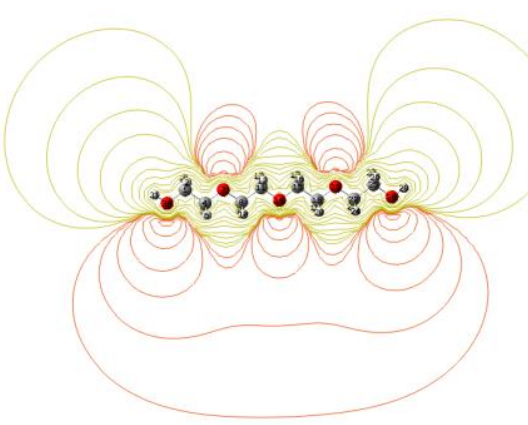

(a)

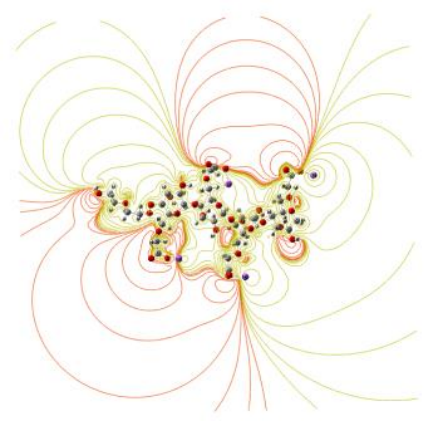

(c)

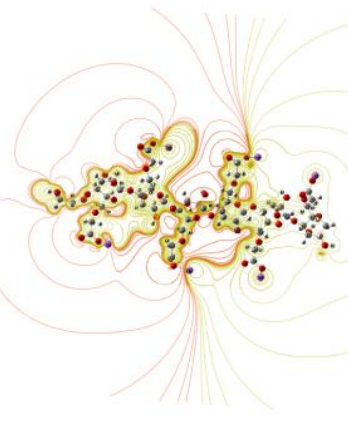

(b)

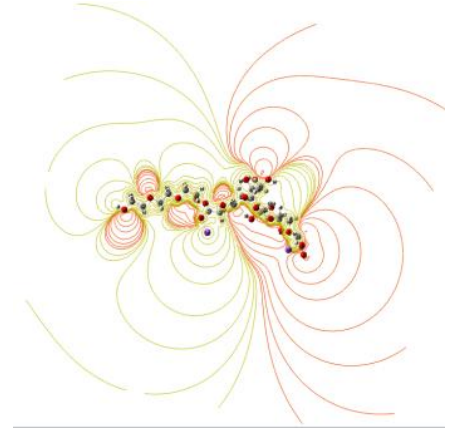

(d)

Figure 3. ESP calculated at $\mathrm{B} 3 \mathrm{LYP} / 3-21 \mathrm{~g} *$ as a contour for a) emeraldine base $\mathrm{PEO}, \mathrm{b}) 3 \mathrm{CMC} / 1 \mathrm{PEO}$, c) $2 \mathrm{CMC} / 2 \mathrm{PEO}$, and d) $1 \mathrm{CMC} / 3 \mathrm{PEO}$.

To confirm the results of TDM and HOMO/LUMO bandgap energies, MESP was also calculated for all the studied structures at B3LYB/3-21 $\mathrm{g}^{*}$ level of theory. Figure 3 shows the 
calculated MESP as a contour for a) emeraldine base PEO, b) 3CMC/1PEO, c) 2CMC/2PEO, and d) 1CMC/3PEO, respectively.

Based on the previous work on MESP, it was stated that a molecule's reactivity could be determined by following, in its strength, a color mapping. This mapping of colors refers to the distribution of electronic charges within the molecules under study. It starts from red to orange, yellow, green, and blue. The red color refers to the high electronegative side and hence highly reactive molecules. However, the yellow and blue colors refer to neutral and electropositive charges [38-42]. As shown in figure 3, the red color was located only around one edge of $\mathrm{CMC}$, which was proven by the HOMO/LUMO results and that the electro-negativity of emeraldine base CMC was highly around this side.

The previous changes occurred in TDM, HOMO/LUMO bandgap energy, and MESP values may be due to the strong interaction occurred between CMC and PEO as CMC contains two of the most important functional groups: hydroxyl and carboxylic groups ( $\mathrm{OH}$ and $\mathrm{COO}-)$ while PEO contains the ether group (-O-).

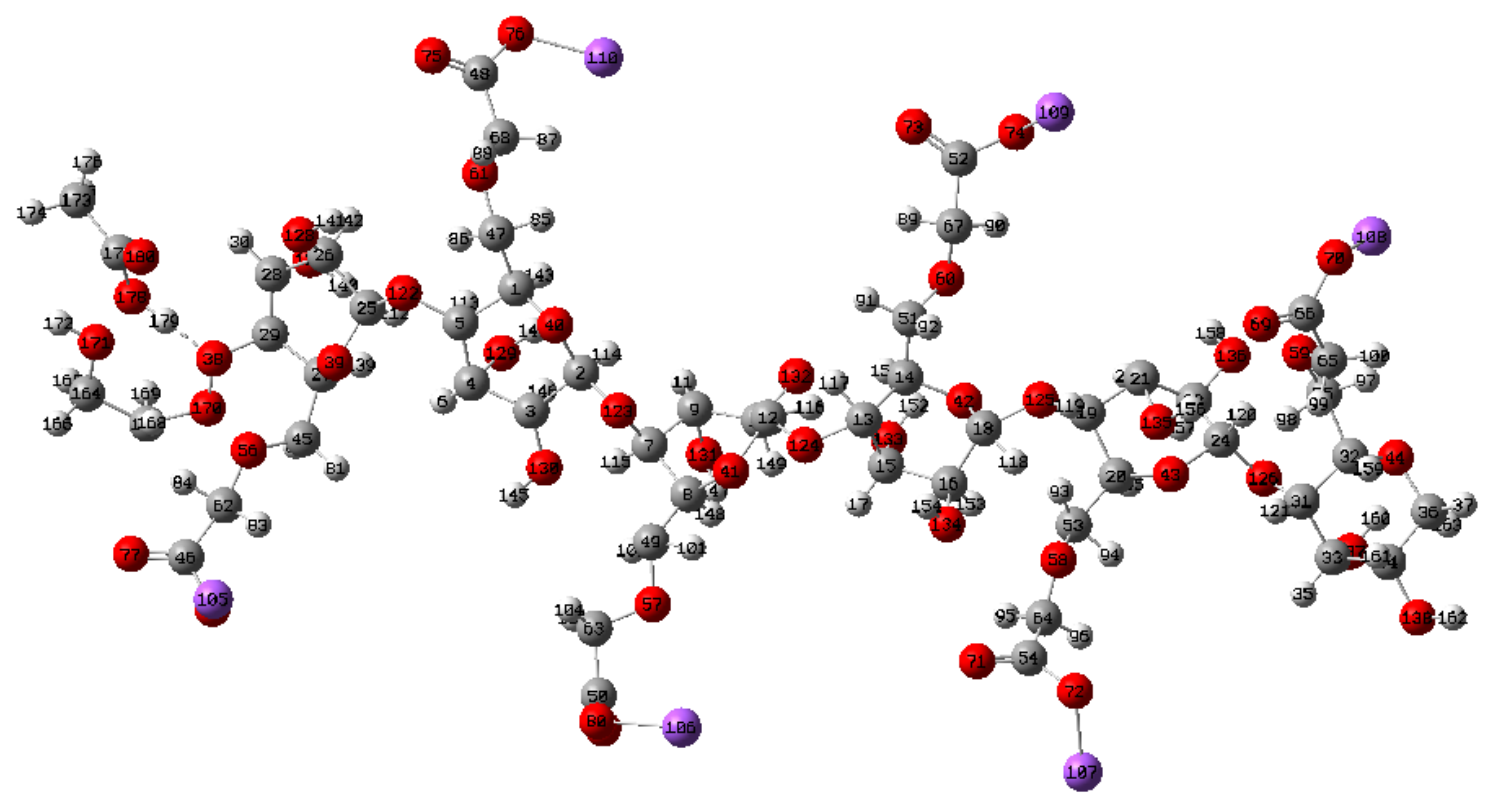

(a)

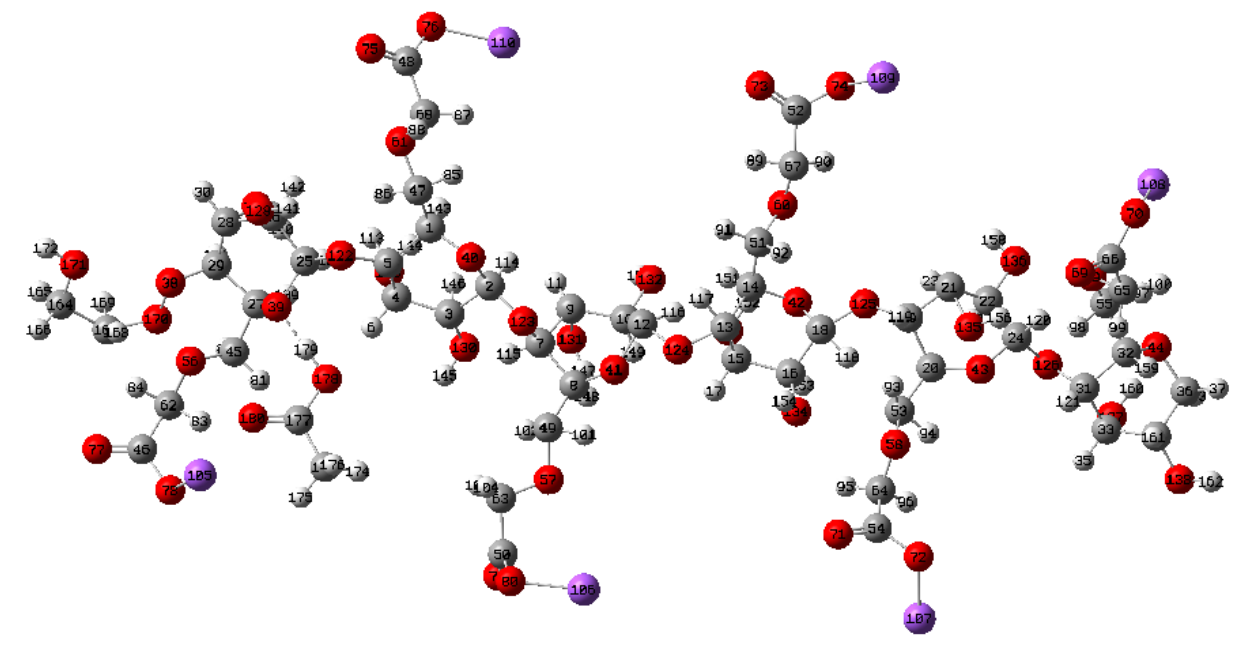

(b) 


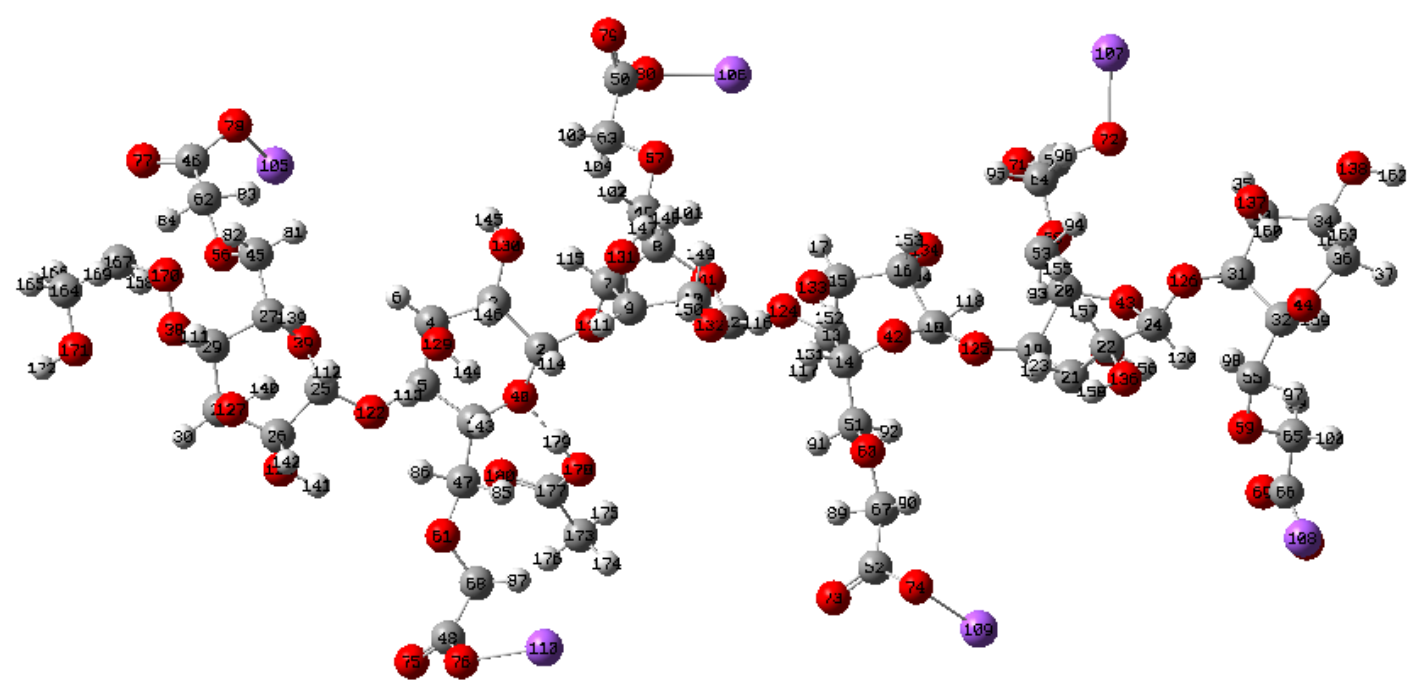

(c)

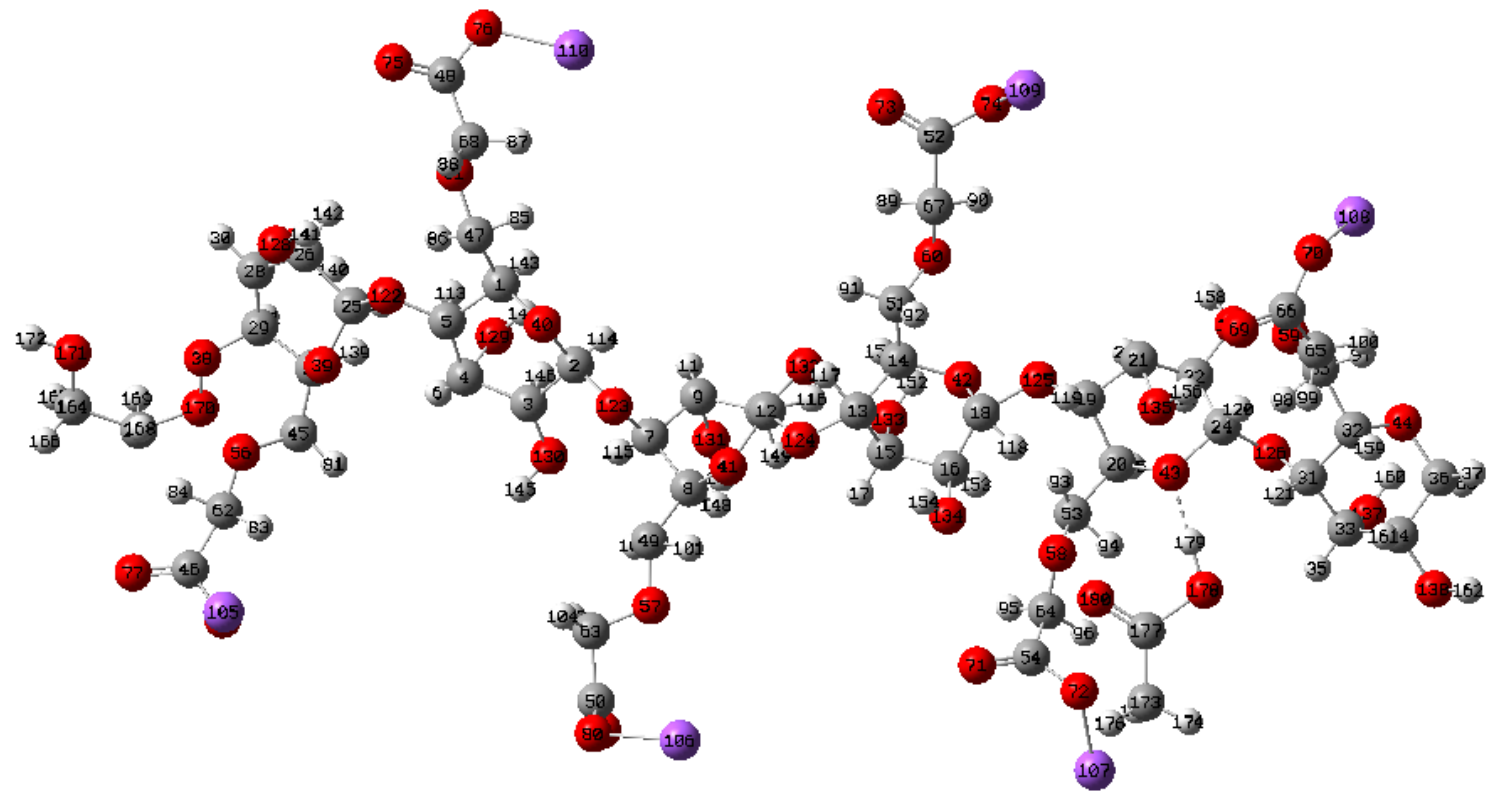

(d)

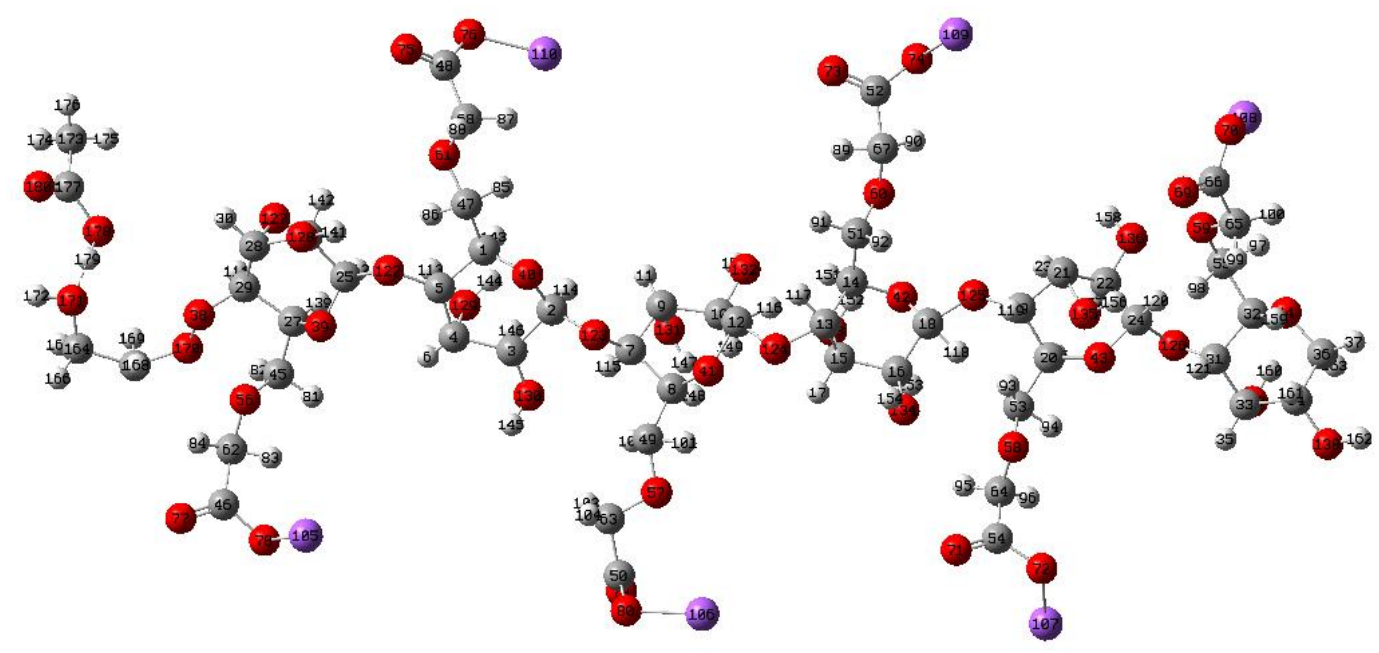

(e)

Figure 4. The optimized structure of: a) $3 \mathrm{CMC} / 1 \mathrm{PEO} /\left(\mathrm{O}_{38}\right)$ acetic acid, b) $3 \mathrm{CMC} / 1 \mathrm{PEO} /\left(\mathrm{O}_{39}\right)$ acetic acid, c) $3 \mathrm{CMC} / 1 \mathrm{PEO} /\left(\mathrm{O}_{40}\right)$ acetic acid, d) $3 \mathrm{CMC} / 1 \mathrm{PEO} /\left(\mathrm{O}_{43}\right)$ acetic acid and e) $3 \mathrm{CMC} / 1 \mathrm{PEO} /\left(\mathrm{O}_{171}\right)$ acetic acid. 


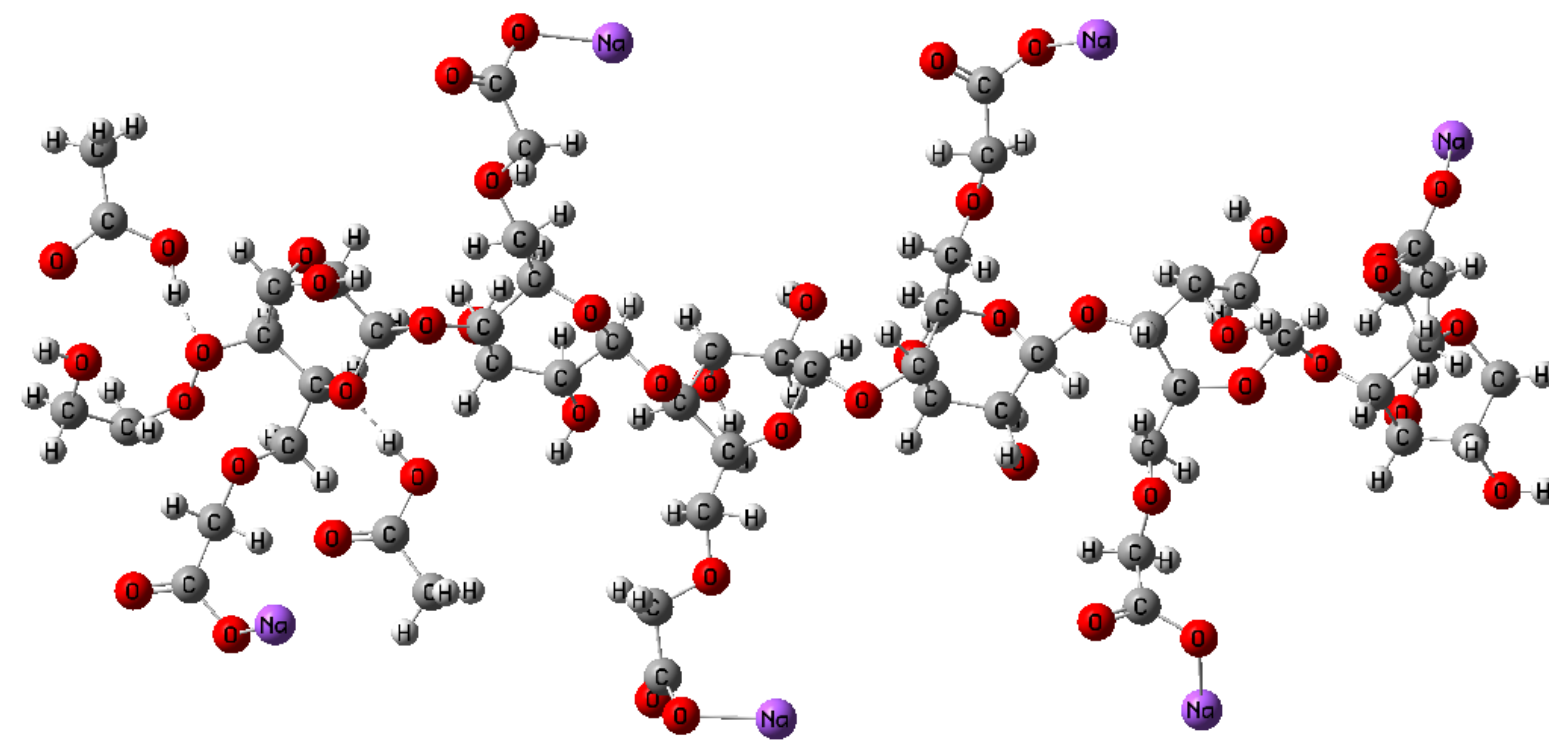

(a)

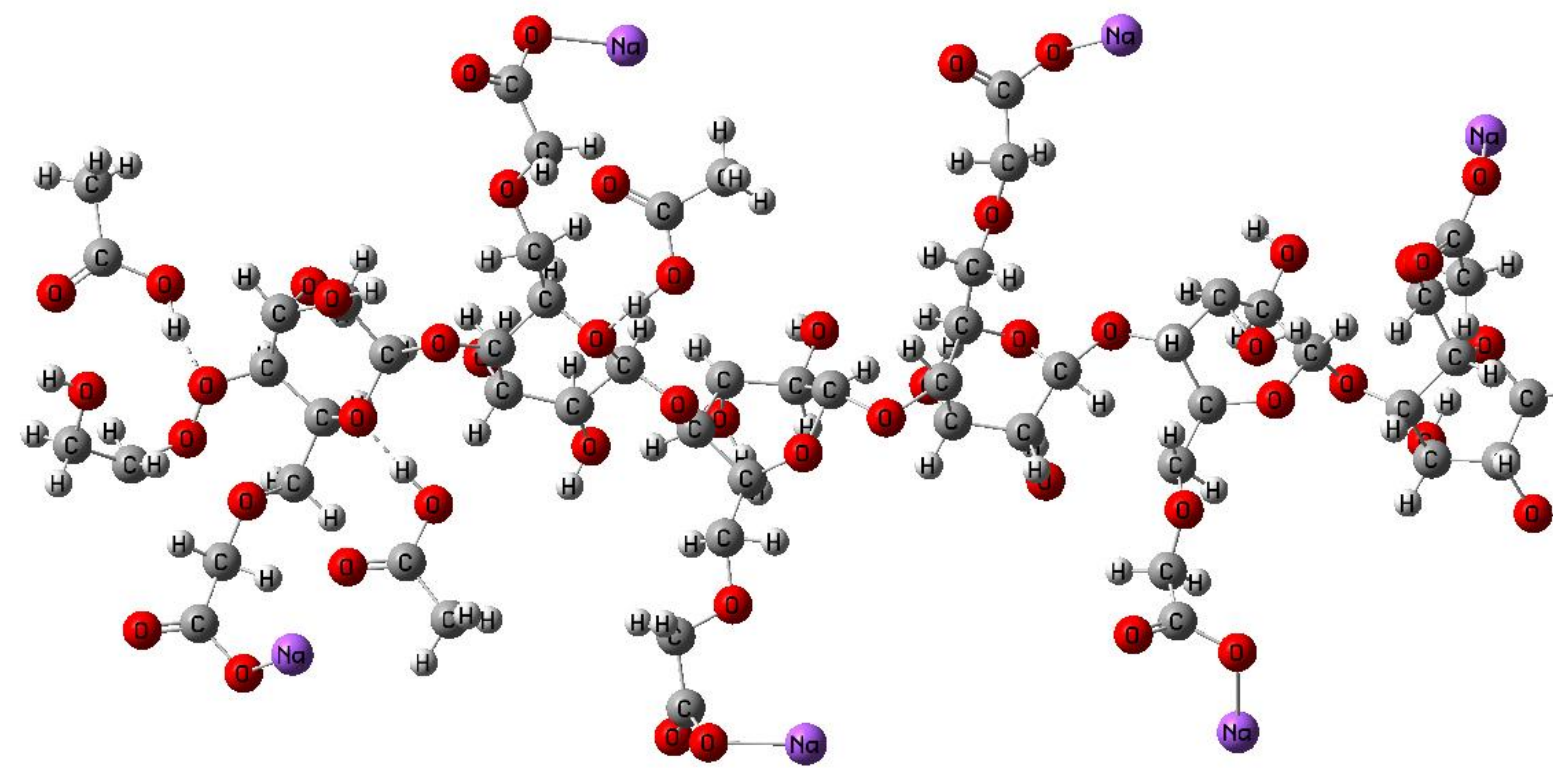

(b)

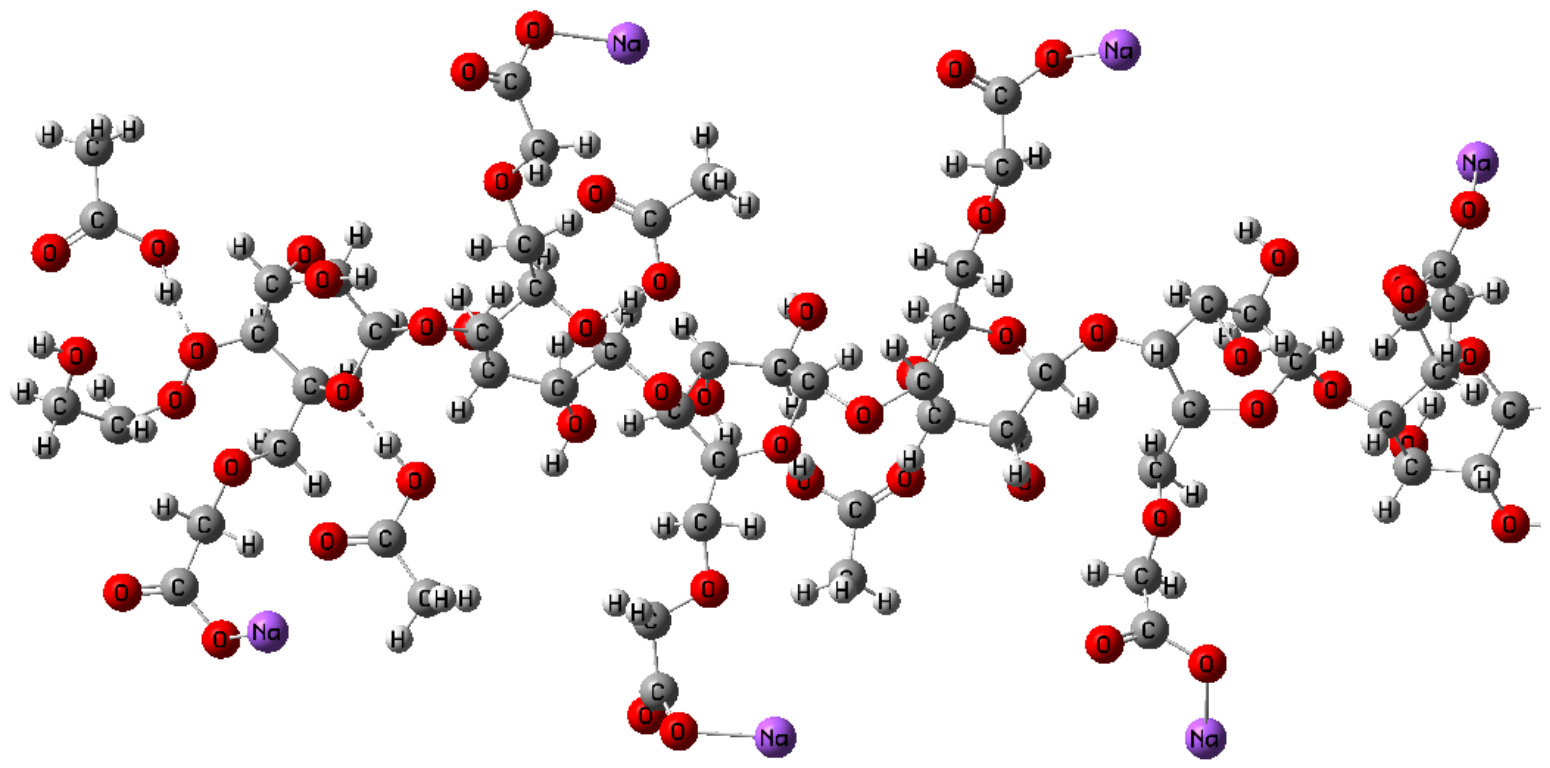

(c) 


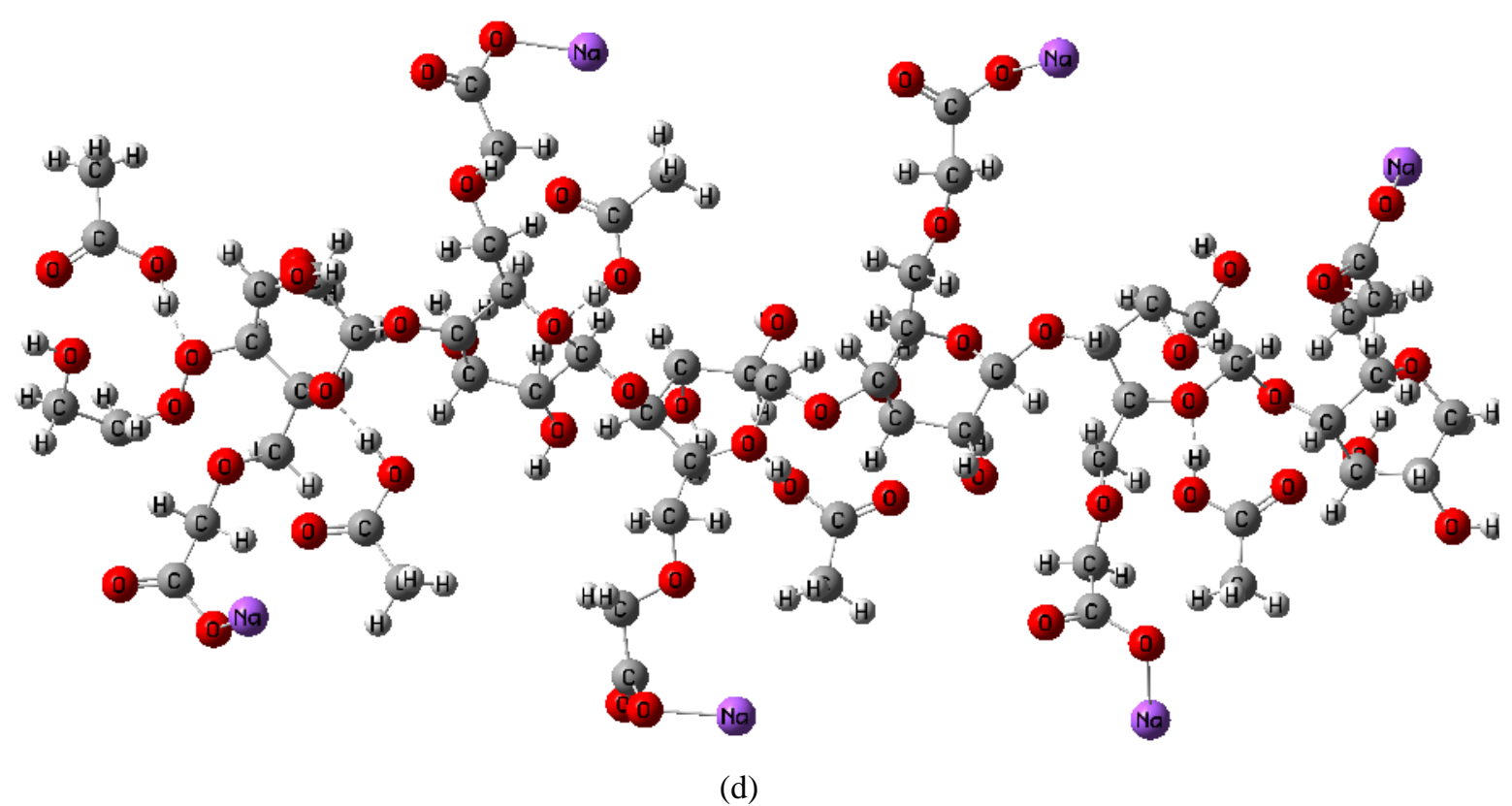

Figure 5. The optimized structure for: a) 3CMC/1PEO/2 acetic acid, b) 3CMC/1PEO/3 acetic acid, c) $3 \mathrm{CMC} / 1 \mathrm{PEO} / 4$ acetic acid and $\mathrm{d}$ ) and 3CMC/1PEO/5 acetic acid.

Table 2. B3LYP/3-21g* calculated TDM as Debye and HOMO-LUMO bandgap energy as eV for 3CMC/1PEO interacted with acetic acid at five different positions: $\mathrm{O}_{38}, \mathrm{O}_{39}, \mathrm{O}_{40}, \mathrm{O}_{43}$, and $\mathrm{O}_{171}$.

\begin{tabular}{|c|c|c|}
\hline Structure & TDM & $\Delta \mathbf{E}$ \\
\hline 3CMC/1PEO/(O 38$)$ acetic acid & 35.3018 & 0.1116 \\
\hline 3CMC/1PEO/(O39) acetic acid & 35.3659 & 0.1116 \\
\hline 3CMC/1PEO/(O40) acetic acid & 35.3075 & 0.2027 \\
\hline 3CMC/1PEO/(O43) acetic acid & 35.0787 & 0.1143 \\
\hline 3CMC/1PEO/(O/171) acetic acid & 35.0623 & 0.2269 \\
\hline
\end{tabular}

For SPEs based on CMC/PEO/acetic acid, as CMC/PEO with a blending ratio of 3/1(i.e., trimer $\mathrm{CMC} /$ monomer PEO) requires a small amount of energy to have occurred, then acetic acid can be added to the last blending ratio to increase the reactivity and enhance the electronic properties more. The effect of acetic acid addition on CMC/PEO's electronic properties was studied only in terms of TDM and HOMO/LUMO bandgap energy. As the studied blend contains several $\mathrm{OH}$ groups in its structure, acetic acid can interact with CMC/PEO blend via the hydroxyl group of oxygen atom number 38, 39, 40, 43, and 171 . Figure 4 shows the optimized structure for $\mathrm{CMC} / \mathrm{PEO}$ /acetic acid models at the different interaction positions. Also, TDM and HOMO/LUMO band gap energies were calculated at B3LYP/3-21 g*. Table 2 presents the calculated TDM of 3CMC/1PEO/ X acetic acid model molecules where $\mathrm{X}$ refers to the number of the oxygen atom of the hydroxyl groups to which acetic acid was attached. Where, TDM equals: 35.3018, 35.2659, 35.3075, 35.7873 and 35.0623 Debye for 3CMC/1PEO/ $\mathrm{O}_{38}$ acetic acid, 3CMC/1PEO/ $\mathrm{O}_{39}$ acetic acid, 3CMC/1PEO/ $\mathrm{O}_{40}$ acetic acid, 3CMC/1PEO/ $\mathrm{O}_{43}$ acetic acid and 3CMC/1PEO/ $\mathrm{O}_{171}$ acetic acid respectively.

Based on the obtained results, acetic acid addition's position has a negligible effect on TDM values. While the HOMO/LUMO band gap energy was affected slightly where it equals $0.1116,0.1116,0.2027,0.1143$, and $0.2269 \mathrm{eV}$ for the reactions processed through the oxygen atom number 38, 39, 40, 43, and 171, respectively. As presented in Table 2 that the interaction processed through the oxygen atom number 39 possesses the highest TDM and smallest bandgap, in comparison with other studied positions, then we can start to increase the concentration of acetic acid from this level of calculations. 
However, it's worth mentioning that acetic acid addition enhances the electronic properties of CMC/PEO blends where the TDM increased to approximately 35.3659 Debye, and the bandgap decreased to approximately $0.1116 \mathrm{eV}$ in comparison with the values obtained in table 1. Additionally, increasing acetic acid content will increase the TDM values and decrease the HOMO/LUMO band gap energy values, as presented in table 3. Figure 5 presents the optimized models proposed for the model molecules representing 3CMC/1PEO/2 acetic acid, 3CMC/1PEO/ 3 acetic acid, 3CMC/1PEO/4 acetic acid, and 3CMC/1PEO/5 acetic acid, respectively.

Table 3. B3LYP/3-21g* calculated TDM as Debye and HOMO-LUMO bandgap energy as eV for 3CMC/1PEO/2 acetic acid, 3CMC/1PEO/3 acetic acid, 3CMC/1PEO/4 acetic acid, and 3CMC/1PEO/5 acetic acid.

\begin{tabular}{l|l|l} 
Structure & TDM & $\Delta \mathbf{E}$ \\
\hline 3CMC/1PEO/2acetic acid & 42.2412 & 0.0656 \\
\hline 3CMC/1PEO/3acetic acid & 53.2794 & 0.0159 \\
\hline 3CMC/1PEO/4acetic acid & 50.9184 & 0.0245 \\
\hline 3CMC/1PEO/5acetic acid & 45.8152 & 0.0272
\end{tabular}

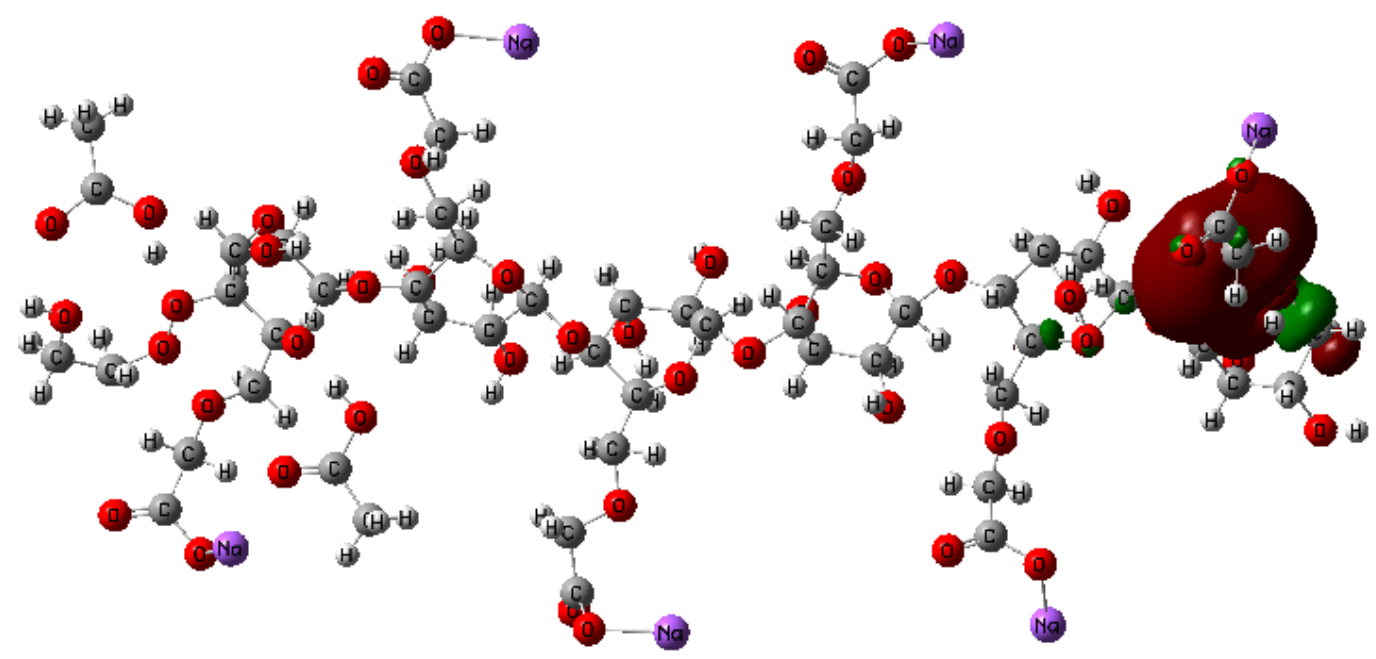

(a)

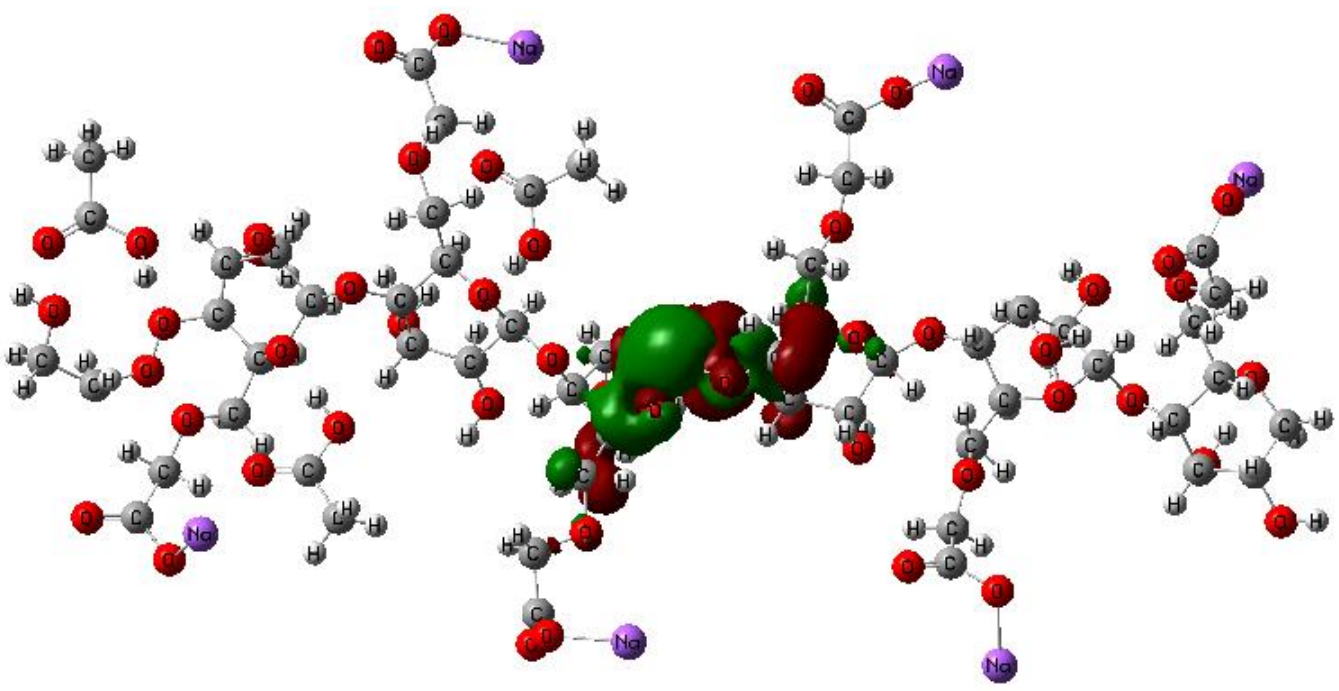

(b) 


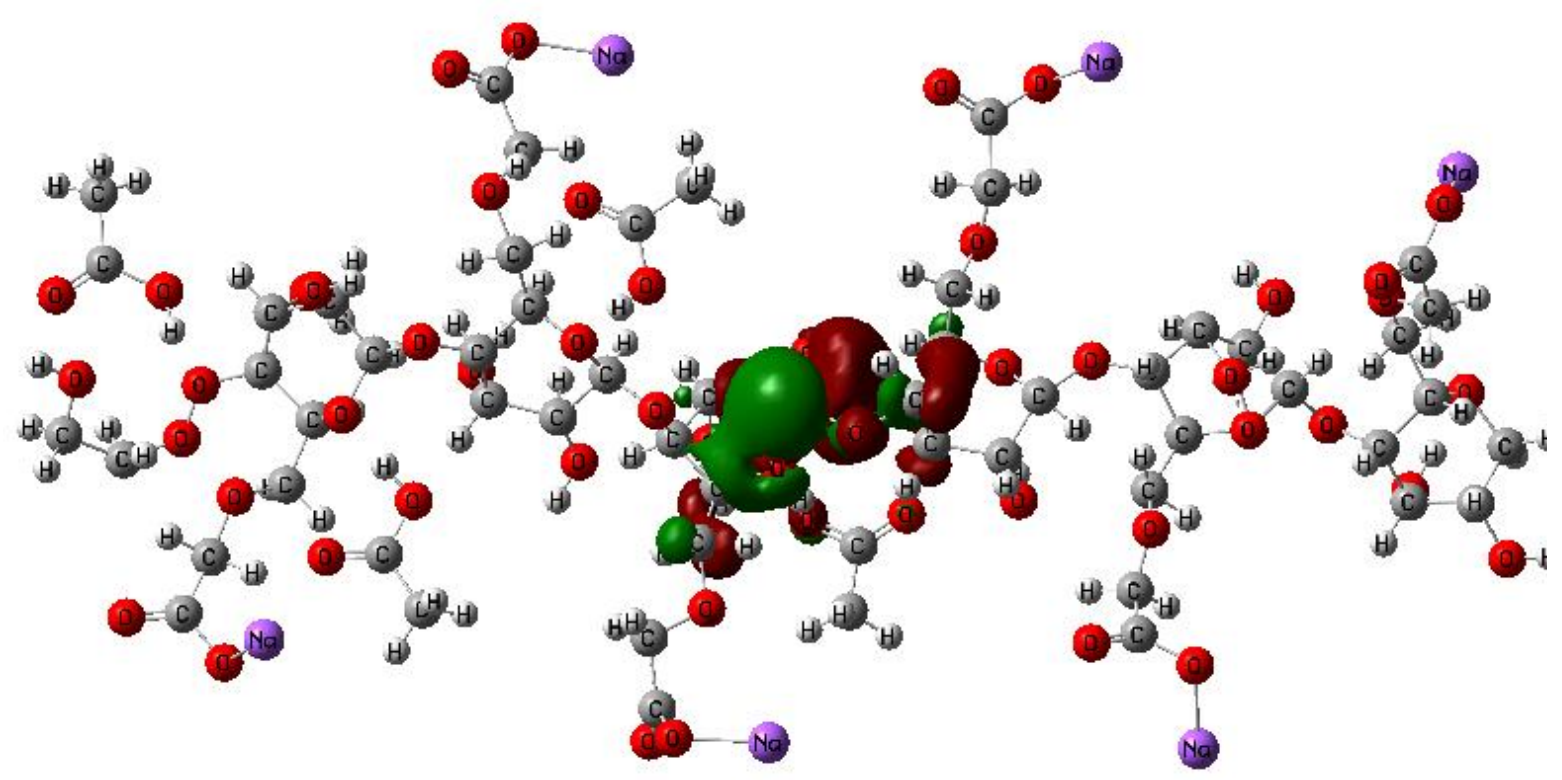

(c)

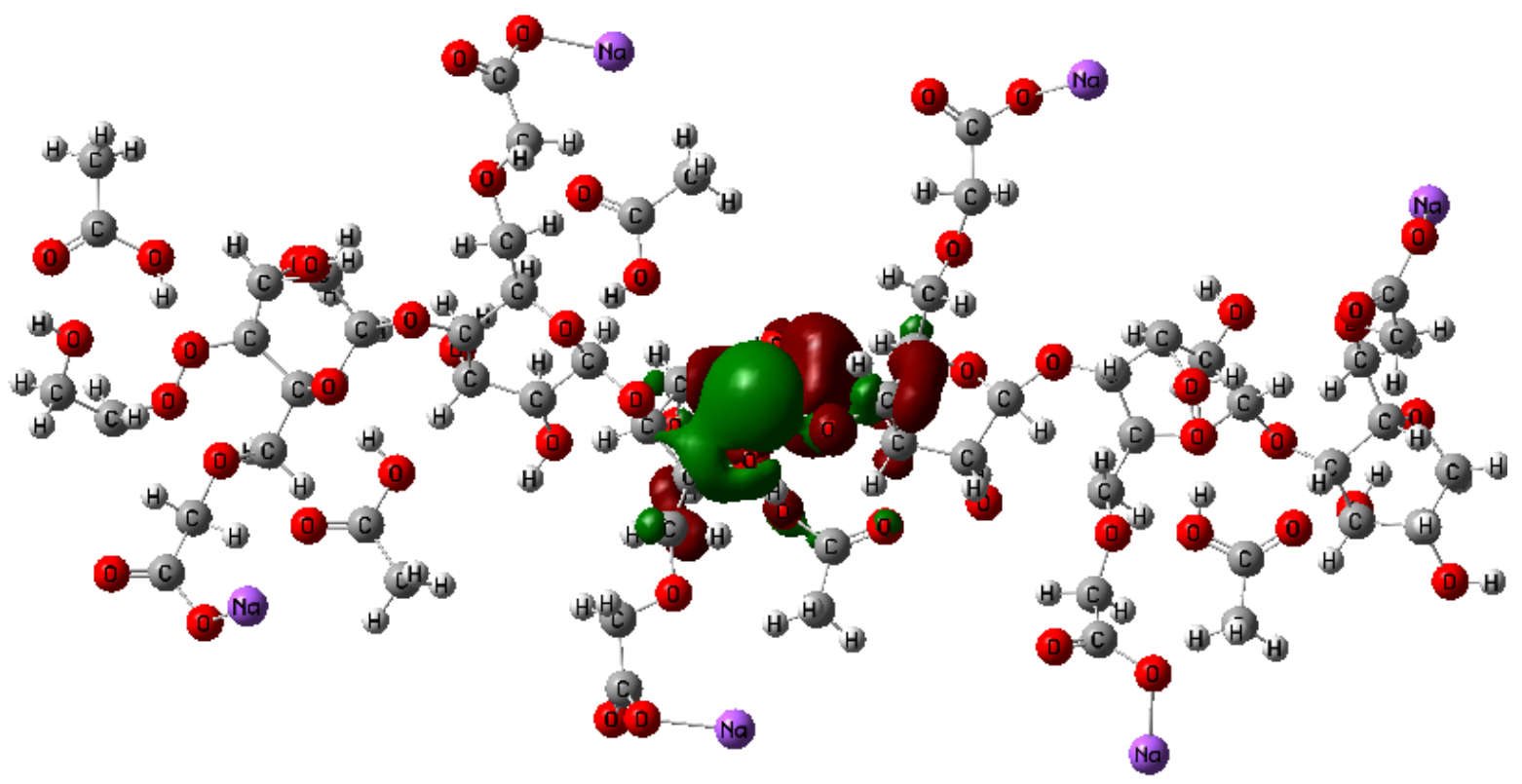

(d)

Figure 6. HOMO/LUMO distribution calculated at B3LYP/3-21g* for a) 3CMC/1PEO/2 acetic acid, b) 3CMC/1PEO/3 acetic acid, c) 3CMC/1PEO/4 acetic acid and d) and 3CMC/1PEO/5 acetic acid.

For the studied models of 3CMC/1PEO/2 acetic acid, 3CMC/1PEO/3 acetic acid, 3CMC/1PEO/4 acetic acid, and 3CMC/1PEO/5 acetic acid, TDM increased to 42.2412, 53.2794, 50.9184, and 45.8152 Debye, respectively. The table observed that TDM increased with increasing acetic acid content up to 3 units (i.e., 3CMC/1PEO/ 3 acetic acid), but it decreased at higher contents. Meanwhile, the HOMO/LUMO band gap energy has a considerable enhancement in its values, as shown in table 3, where it decreased to 0.0656, $0.0159,0.0245$, and $0.0272 \mathrm{eV}$ to increasing acetic acid concentration. The enhancement of the TDM values was attributed to the increment of CMC/PEO electro-negativity as the number of charge carriers increased with acetic acid. This increase in charge carriers means that the mobility and conductivity increased with increasing acetic acid concentration. Also, these increase in conductivity and charge carrier's mobility was confirmed by the observable decrease in HOMO/LUMO energy gap values. The changes that occurred in the HOMO/LUMO band gap energy were presented in figure 6. Also, it was clear from the figure 
that the HOMO and the LUMO were distributed around the edge in the case of $3 \mathrm{CMC} / 1 \mathrm{PEO} / 2$ acetic acid but, they were distributed at the middle of the structure for higher than 2 units of acetic acid that were for 3CMC/1PEO/3acetic acid, 3CMC/1PEO/4acetic acid, and $3 \mathrm{CMC} / 1 \mathrm{PEO} / 5$ acetic acid.

It was clear from the table that the 3CMC/1PEO SPEs doped with different acetic acid concentrations become more electronegative and can be used as a membrane material in energy storage devices, where TDM increased and HOMO/LUMO band gap energy decreased.

\section{Conclusions}

Total dipole moment TDM and HOMO/LUMO bandgap energy shoe direct relation with the given molecular structure's reactivity. Accordingly, both are good indicators for the electronic properties of the studied polymer blends. A computational study was carried out using DFT: B3LYB/3-21g* level of theory to design new membrane materials based on blends of CMC/PEO and CMC/PEO treated with acetic acid. It was indicated that treatment with acetic acid made the studied blend more electronegative. More precisely, TDM increased to 40.3945 Debye for CMC/PEO and to 53.2794 Debye for CMC/PEO/ acetic acid while, the $\mathrm{HOMO} / \mathrm{LUMO}$ bandgap decreased to $0.0705 \mathrm{eV}$ and $0.0159 \mathrm{eV}$, respectively.

Based on obtained the results, it could be concluded that the model molecules representing $\mathrm{CMC} / \mathrm{PEO}$ and $\mathrm{CMC} / \mathrm{PEO}$ /acetic acid could be successfully applied in the field of electrochemical devices as they have major feature including simplicity of structures, accurate computations, time-saving, high sensitivity and high reactivity.

\section{Funding}

This research received no external funding.

\section{Acknowledgments}

This research has no acknowledgment.

\section{Conflicts of Interest}

The authors declare no conflict of interest.

\section{References}

1. Badry, R.; Ibrahim, A.; Gamal, F.; Ibrahim, S.A.; Ezzat, H.; Elhaes, H.; Ibrahim, M. Modeling the Effect of Zinc Oxide on the Electronic Properties of Polyvinyl Alcohol. Egypt. J. Chem. 2020, https://doi.org/10.21608/EJCHEM.2020.27245.2564.

2. Refaat, A.; Elhaes, H.; Ammar, N.S.; Ibrahim, H.S.; Ibrahim, M. Green Route for the Removal of Pb from Aquatic Environment. Comb Chem High Throughput Screen 2020, 23, 587-598, https://doi.org/10.2174/1386207323666200127123349.

3. Bayoumy, A.M.; Ibrahim, M.; Omar, A. Mapping molecular electrostatic potential (MESP) for fulleropyrrolidine and its derivatives. Optical and Quantum Electronics 2020, 52, 1-13, https://doi.org/10.1007/s11082-020-02467-6.

4. Refaat, A.; Ibrahim, M.A.; Elhaes, H.; Badry, R.; Ezzat, H.; Yahia, I.S.; Zahran, H.Y.; Shkir, M. Geometrical, vibrational and physical properties of polyvinyl chloride nanocomposites: Molecular modeling approach. Journal of Theoretical and Computational Chemistry 2019, 18, https://doi.org/10.1142/S0219633619500378.

5. Fahmy, A.; Khafagy, R.M.; Elhaes, H.; Ibrahim, M.A. Molecular properties of polyvinyl alcohol/ sodium alginate composite. Biointerface Research in Applied Chemistry 2020, 10, 4734-4739, https://doi.org/10.33263/BRIAC101.734739. 
6. Ezzat, H.A.; Hegazy, M.A.; Nada, N.A.; Osman, O.; Ibrahim, M.A. Application of natural polymers enhanced with $\mathrm{ZnO}$ and $\mathrm{CuO}$ as humidity sensor. NRIAG Journal of Astronomy and Geophysics 2020, 9 , 586-597, https://doi.org/10.1080/20909977.2020.1821573.

7. Menazea, A.A.; Ezzat, H.A.; Omara, W.; Basyouni, O.H.; Ibrahim, S.A.; Mohamed, A.A.; Tawfik, W.; Ibrahim, M.A. Chitosan/graphene oxide composite as an effective removal of $\mathrm{Ni}, \mathrm{Cu}, \mathrm{As}, \mathrm{Cd}$ and $\mathrm{Pb}$ from wastewater. Computational and Theoretical Chemistry 2020, 1189, https://doi.org/10.1016/j.comptc.2020.112980.

8. Bayoumy, A.M.; Refaat, A.; Yahia, I.S.; Zahran, H.Y.; Elhaes, H.; Ibrahim, M.A.; Shkir, M. Functionalization of graphene quantum dots (GQDs) with chitosan biopolymer for biophysical applications. Optical and Quantum Electronics 2019, 52, https://doi.org/10.1007/s11082-019-2134-z.

9. Ibrahim, M. Application of Graphene/Nickel Oxide Composite as a Humidity Sensor. Egyptian Journal of Chemistry 2020, https://doi.org/10.21608/EJCHEM.2020.36453.2753.

10. Ibrahim, M. Molecular Modeling Analyses and Vibrational Characteristics for Nitromethane. Egyptian Journal of Chemistry 2020, https://doi.org/10.21608/EJCHEM.2020.35452.2736.

11. Ibrahim, M.; Ezzat, H.; Elhaes, H. Molecular Modeling Applied For Carbon Nano Materials. Egyptian Journal of Chemistry 2020, https://doi.org/10.21608/EJCHEM.2020.26861.2551.

12. Al-Bagawi, A.H.; Bayoumy, A.M.; Ibrahim, M.A. Molecular modeling analyses for graphene functionalized with Fe3O4 and NiO. Heliyon 2020, 6, https://doi.org/10.1016/j.heliyon.2020.e04456.

13. Abdel-Karim, A.; Elhaes, H.; El-Kalliny, A.S.; Badawy, M.I.; Ibrahim, M.; Gad-Allah, T.A. Probing protein rejection behavior of blended PES-based flat-sheet ultrafiltration membranes: A density functional theory (DFT) study. Spectrochimica Acta Part A: Molecular and Biomolecular Spectroscopy 2020, 238, https://doi.org/10.1016/j.saa.2020.118399.

14. Elhaes, H.; Saleh, N.A.; Ibrahim, M.A. Molecular Modeling Applications of Some Bio-Polymers Blends as Biosensor. Sensor Letters 2018, 16, 539-547, https://doi.org/10.1166/s1.2018.3974.

15. Abdelsalam, H.; Saroka, V.A.; Ali, M.; Teleb, N.H.; Elhaes, H.; Ibrahim, M.A. Stability and electronic properties of edge functionalized silicene quantum dots: A first principles study. Physica E: Lowdimensional Systems and Nanostructures 2019, 108, 339-346, https://doi.org/10.1016/j.physe.2018.07.022.

16. Galal, A.M.F.; Atta, D.; Abouelsayed, A.; Ibrahim, M.A.; Hanna, A.G. Configuration and molecular structure of 5-chloro-N-(4-sulfamoylbenzyl) salicylamide derivatives. Spectrochimica Acta Part A: Molecular and Biomolecular Spectroscopy 2019, 214, 476-486, https://doi.org/10.1016/j.saa.2019.02.070.

17. Abdelsalam, H.; Teleb, N.H.; Yahia, I.S.; Zahran, H.Y.; Elhaes, H.; Ibrahim, M.A. First principles study of the adsorption of hydrated heavy metals on graphene quantum dots. Journal of Physics and Chemistry of Solids 2019, 130, 32-40, https://doi.org/10.1016/j.jpcs.2019.02.014.

18. Saleh, N.A.; Elhaes, H.; Ibrahim, M. Design and Development of Some Viral Protease Inhibitors by QSAR and Molecular Modeling Studies. Viral Proteases and Their Inhibitors 2017, 25-58, https://doi.org/10.1016/B978-0-12-809712-0.00002-2.

19. Becke, A.D. Density- functional thermo-chemistry. III. The role of exact exchange. J. Chem. Phys. 1993, 98, 5648-5652, https://doi.org/10.1063/1.464913.

20. Becke, A.D. Density-functional thermochemistry. IV. A new dynamical correlation functional and implications for exact-exchange mixing. J. Chem. Phys. 1996, 104, 1040-1046, https://doi.org/10.1063/1.470829.

21. Raghavachari, K. Perspective on "Density functional thermochemistry. III. The role of exact exchange". Theor. Chem. Acc. 2000, 103, 361-363, https://doi.org/10.1007/s002149900065.

22. Lee, C.; Yang, W.; Parr, R.G. Development of the Colle-Salvetti correlation-energy formula into a functional of the electron density. Physical Review B 1988, 37, 785-789, https://doi.org/10.1103/PhysRevB.37.785.

23. Miehlich, B.; Savin, A.; Stoll, H.; Preuss, H. Results obtained with the correlation energy density functionals of becke and Lee, Yang and Parr. Chemical Physics Letters 1989, 157, 200-206, https://doi.org/10.1016/0009-2614(89)87234-3.

24. Badry, R.; Ezzat, H.A.; El-Khodary, S.; Morsy, M.; Elhaes, H.; Nada, N.; Ibrahim, M. Spectroscopic and thermal analyses for the effect of acetic acid on the plasticized sodium carboxymethyl cellulose. Journal of Molecular Structure 2021, 1224, https://doi.org/10.1016/j.molstruc.2020.129013.

25. El-Bana, M.S.; Mohammed, G.; El Sayed, A.M.; El-Gamal, S. Preparation and characterization of $\mathrm{PbO} /$ carboxymethyl cellulose/polyvinylpyrrolidone nanocomposite films. Polymer Composites 2018, 39, 3712-3725, https://doi.org/10.1002/pc.24402.

26. Morsi, M.A.; Abdelaziz, M.; Oraby, A.H.; Mokhles, I. Structural, optical, thermal, and dielectric properties of polyethylene oxide/carboxymethyl cellulose blend filled with barium titanate. Journal of Physics and Chemistry of Solids 2019, 125, 103-114, https://doi.org/10.1016/j.jpcs.2018.10.009.

27. Morsi, M.A.; Abdelaziz, M.; Oraby, A.H.; Mokhles, I. Effect of lithium titanate nanoparticles on the structural, optical, thermal and electrical properties of polyethylene oxide/carboxymethyl cellulose blend. Journal of Materials Science: Materials in Electronics 2018, 29, 15912-15925, https://doi.org/10.1007/s10854-018-9677-9. 
28. El-Sayed, S.; Mahmoud, K.H.; Fatah, A.A.; Hassen, A. DSC, TGA and dielectric properties of carboxymethyl cellulose/polyvinyl alcohol blends. Physica B: Condensed Matter 2011, 406, 4068-4076, https://doi.org/10.1016/j.physb.2011.07.050.

29. Kumar, K.K.; Ravi, M.; Pavani, Y.; Bhavani, S.; Sharma, A.K.; Narasimha Rao, V.V.R. Investigations on $\mathrm{PEO} / \mathrm{PVP} / \mathrm{NaBr}$ complexed polymer blend electrolytes for electrochemical cell applications. Journal of Membrane Science 2014, 454, 200-211, https://doi.org/10.1016/j.memsci.2013.12.022.

30. Choudhary, S. Structural, optical, dielectric and electrical properties of (PEO-PVP)-ZnO nanocomposites. Journal of Physics and Chemistry of Solids 2018, 121, 196-209, https://doi.org/10.1016/j.jpcs.2018.05.017.

31. Li, W.; Pang, Y.; Liu, J.; Liu, G.; Wang, Y.; Xia, Y. A PEO-based gel polymer electrolyte for lithium ion batteries. RSC Advances 2017, 7, 23494-23501, https://doi.org/10.1039/C7RA02603J.

32. Mohan, V.M.; Bhargav, P.B.; Raja, V.; Sharma, A.K.; Narasimha Rao, V.V.R. Optical and Electrical Properties of Pure and Doped PEO Polymer Electrolyte Films. Soft Materials 2007, 5, 33-46, https://doi.org/10.1080/15394450701405291.

33. Choudhary, S. Structural and dielectric properties of (PEO-PMMA)-SnO2 nanocomposites. Composites Communications 2017, 5, 54-63, https://doi.org/10.1016/j.coco.2017.07.004.

34. Morsi, M.A.; El-Khodary, S.A.; Rajeh, A. Enhancement of the optical, thermal and electrical properties of PEO/PAM:Li polymer electrolyte films doped with Ag nanoparticles. Physica B: Condensed Matter 2018, 539, 88-96, https://doi.org/10.1016/j.physb.2018.04.009.

35. Rajeh, A.; Morsi, M.A.; Elashmawi, I.S. Enhancement of spectroscopic, thermal, electrical and morphological properties of polyethylene oxide/carboxymethyl cellulose blends: Combined FT-IR/DFT. Vacuum 2019, 159, 430-440, https://doi.org/10.1016/j.vacuum.2018.10.066.

36. Frisch, M.J.; Trucks, G.W.; Schlegel, H.B.; Scuseri, G. E.; Robb, M.A.; Cheeseman, J.R.; Scalmani, G.; Barone, V.; Mennucci, P.B.G.A.; Nakatsuji, H.; Caricato, M.; Li, X.; Hratchian, P.HI.; Izmaylov, A.F.; Bloino, J.; Zheng, G.; Sonnenberg, J.L.; Hada, M.; Ehara, M.; Toyota, K.; Fukuda, R.; Hasegawa, J.; Ishida, M.; Nakajima, T.; Honda, Y.; Kitao, O.; Nakai, H.; Vreven, T.; Montgomery, J.A.; Jr; Peralta, J.E.; Ogliaro, F.; Bearpark, M.; Heyd, J.J.; Brother, E.; Kudin, K.N.; Staroverov, V.N.; Keith, T.; Kobayashi, R.; Normand, .J, Raghavachari, K.; Rendell, A.; Burant, J.C.; Iyengar, S.S.; Tomasi, J.; Cossi, M.; Rega, N.; Millam, J.M.; Klene, M.; Knox, J.E.; Cross, J.B.; Bakken, V.; Adamo, C.; Jaramillo, J.; Gomperts, R.; Stratmann, R.E.; Yazyev, O.; Austin, A.J.; Cammi, R.; Pomelli, C.; Ochterski, J.W.; Martin, R.L.; Morokuma, K.; Zakrzewski, V.G.; Voth, G.A.; Salvador, P.; Dannenberg, J.J.; Dapprich, S.; Daniels, A.D.; Farkas, O.; Foresman, J.B.; Ortiz, J.V.; Cioslowski, J.; Fox, D.J. Gaussian 09, Revision C.01, Gaussian, Inc.; Wallingford CT 2010.

37. Badry, R.; El-Khodary, S.; Elhaes, H.; Nada, N.; Ibrahim, M. The Influence of Moisture on the Electronic Properties of Monomer, Dimer, Trimer and Emeraldine Base Sodium Carboxymethyl Cellulose. Egyptian Journal of Chemistry 2019, 62, 39-56, https://doi.org/10.21608/EJCHEM.2019.12805.1800.

38. Ibrahim, M.; El-Haes, H. Computational spectroscopic study of copper, cadmium, lead and zinc interactions in the environment. Int. J. Environ.Pollut. 2005, 23, 417-424, https://doi.org/10.1504/IJEP.2005.007604.

39. Ibrahim, M.; Mahmoud, A-A. Computational Notes on the Reactivity of some Functional Groups. J. Comput. Theor. Nanosci. 2009, 6, 1523-1526, https://doi.org/10.1166/jctn.2009.1205.

40. Politzer, P.; Laurence, P.R.; Jayasuriya, K. Molecular electrostatic potentials: an effective tool for the elucidation of biochemical phenomena. Environmental Health Perspectives 1985, 61, 191-202, https://doi.org/10.1289/ehp.8561191.

41. Politzer, P.; Murray, J.S. Molecular Electrostatic Potentials: Concepts and Applications. J. Theor. Comput. Chem. 1996, 3.

42. Şahin, Z.S.; Şenöz, H.; Tezcan, H.; Büyükgüngör, O. Synthesis, spectral analysis, structural elucidation and quantum chemical studies of (E)-methyl-4-[(2-phenylhydrazono)methyl]benzoate. Spectrochimica Acta Part A: Molecular and Biomolecular Spectroscopy 2015, 143, 91-100, https://doi.org/10.1016/j.saa.2015.02.032. 